Article

\title{
Remotely Estimating Beneficial Arthropod Populations: Implications of a Low-Cost Small Unmanned Aerial System
}

\author{
Shereen S. Xavier ${ }^{1}$, Alisa W. Coffin ${ }^{2, *}$, Dawn M. Olson ${ }^{3}$ and Jason M. Schmidt ${ }^{1}$ \\ 1 Department of Entomology, University of Georgia, Tifton, GA 31793, USA; \\ shereensxavier@gmail.com (S.S.X.); jschmid2@uga.edu (J.M.S.) \\ 2 Southeast Watershed Research Laboratory, USDA-ARS, Tifton, GA 31793, USA \\ 3 Crop Protection and Management Research Unit, USDA-ARS, Tifton, GA 31793, USA; \\ dawn.olson@ars.usda.gov \\ * Correspondence: alisa.coffin@ars.usda.gov; Tel.: +1-229-386-3665
}

Received: 23 August 2018; Accepted: 14 September 2018; Published: 18 September 2018

\begin{abstract}
Studies show that agricultural land requires investment in the habitat management of non-cropped areas to support healthy beneficial arthropods and the ecosystem services they provide. In a previous small plot study, we manually counted blooms over the season, and found that plots providing greater numbers of flowers supported significantly higher pollinator populations over that of spontaneous weed plots. Here, we examined the potential of deploying an inexpensive small unmanned aerial vehicle (UAV) as a tool to remotely estimate floral resources and corresponding pollinator populations. Data were collected from previously established native wildflower plots in 19 locations on the University of Georgia experimental farms in South Georgia, USA. A UAV equipped with a lightweight digital camera was deployed to capture images of the flowers during the months of June and September 2017. Supervised image classification using a geographic information system (GIS) was carried out on the acquired images, and classified images were used to evaluate the floral area. The floral area obtained from the images positively correlated with the floral counts gathered from the quadrat samples. Furthermore, the floral area derived from imagery significantly predicted pollinator populations, with a positive correlation indicating that plots with greater area of blooming flowers contained higher numbers of pollinators.
\end{abstract}

Keywords: UAV floral detection; image classification; floral provisioning; habitat management; pollinators; agricultural buffers; floral area; long term agroecosystem research (LTAR)

\section{Introduction}

Agricultural landscape diversification is an important strategy for ameliorating the loss of biodiversity and boosting ecosystem services, such as biological control and pollination, provided by beneficial organisms [1,2]. In recent years, the concept of habitat management has been promoted as a strategy for diversifying agricultural landscapes. Habitat management encompasses several approaches which may occur within-crop, within-farm, or within-landscape. One form of habitat management is the utilization of wildflower strips sown at field margins [3,4], or within fields [5] to attract beneficial insects, or to enhance the pollination and biocontrol of nearby crops. Numerous studies have evaluated and demonstrated the potential of wildflowers in agricultural systems for providing ecosystem services [3-7]. Evidence shows that the amount of floral resources (quantity of pollen or nectar production) and the type or diversity of flowering species has a positive effect on pollinator visits [8,9].

Given the potential for wildflowers to improve agricultural sustainability, there is need to develop monitoring tools to estimate floral resources prior to recommendations for habitat management. 
Apart from the traditional method of quantifying flowers through manual counts, recent advances have utilized digital imagery to quantify floral counts. The segmentation and classification of remotely sensed imagery offers a potentially efficient method to measure floral resources [10]. Until recently, remote sensing for vegetation mapping in agriculture has relied extensively on satellite imagery or low-resolution aerial imagery. These images are very effective for monitoring crop production over the season, and for understanding critical information about regional, national and global cropland trends [11]. However, optical satellite imagery is limited in some regions due to cloud cover [12], and neither low-frequency, fine-resolution aerial imagery, nor high-frequency, coarse-resolution satellite imagery allows for monitoring of the more rapid, fine scale changes in agricultural environments. Over the past fifteen years, the commercial development of small unmanned aerial systems (or unmanned aerial vehicles; i.e., UAVs) consisting of light-weight sensors and wireless receivers, combined with small on-board global navigational satellite system (GNSS) receivers, internal measurement units (IMUs), and navigational software, have operationalized precise automated and manual flights for high resolution vegetation mapping [13-15], potentially filling this important data gap.

Sensors borne on UAVs allow for collection of data at very high spatial resolutions $(<50 \mathrm{~cm}$ ground sample distance), and with little to no latency [16-18]. Once data from the UAV sensors are collected, several image segmentation and classification methods are available for analyzing vegetation patterns, exploiting differences in spectral bands from high resolution color images. For example, Biradar \& Shrikhande [19], achieved an overall accuracy of $92 \%$ in classifying marigold flowers in greenhouses from images captured using a digital camera. Siraj et al. [20] applied neural networks and machine learning to segment the features of flowers. Because different plants and flowers have distinct colors and textures, traditional image processing methods such as color and texture analysis can be used to segment pixels and characterize the vegetation of a given area [19,21].

While commercially available UAVs for crop monitoring are becoming a mainstay of the precision agriculture toolbox, UAV use in agricultural and natural systems research is still being tested in a diversity of situations. Data from UAV-borne sensors have been used to provide indirect estimates of biomass, grain yield [22], and nitrogen status [23], and the output of multi-spectral sensors can produce an array of vegetation indices, including the normalized difference of the vegetation index (NDVI) [24]. UAVs are employed to detect and monitor pest infestations [25,26], analyze the structure of vegetation [27], detect nutrient deficiencies, and monitor weed and flower density in crop fields [28-30]. Müllerová et al. [31] recently demonstrated that UAV imagery could be used to successfully differentiate between flowers of different invasive species. Michez et al. [32] detected and classified flowers of Heracleum mantegazzianum (giant hogweed) with high accuracy. Importantly, analysis of UAV images yielded higher accuracy in detection of black locust (Robinia pseudoaccacia) blooms when compared to satellite imagery [31], and yellow flag iris (Iris psedacorus) in contrast with field surveys [33]. UAV data are beginning to be used to estimate arthropod populations, as shown by Carl et al. [34], wherein they linked black locust flower density to nectar production as a food source for the honey bee, Apis mellifera.

These developments suggest that the application of a UAV-borne sensor coupled with image processing techniques for the classification of floral resources [35] could act as important tools for monitoring and predicting the populations of beneficial arthropods such as pollinators. While the use of customized UAVs with expensive calibrated sensors may work best for research applications, operationalizing commercially available UAVs with low-cost cameras is more practical for agricultural producers and consultants.

In this study we: (1) compared flower areas derived from high-resolution UAV imagery with flower counts from traditional plant ecology methods; (2) developed a method to analyze and classify flowers from UAV images; and (3) predicted patterns of beneficial arthropod populations from the floral area obtained in the classification process. In so doing, we demonstrate the use of a low-cost 
commercial UAVs for indirectly monitoring floral resources and estimating pollinator density in agricultural landscapes.

\section{Materials and Methods}

\subsection{Field Sites}

Nineteen conservation buffer sites on marginal land distributed across University of Georgia experimental farms in Tifton, GA, were observed for this study (Figure 1). Each experimental buffer plot was $34 \mathrm{~m} \times 10 \mathrm{~m}\left(340 \mathrm{~m}^{2}\right)$. Plots contained a $2 \mathrm{~m} \times 30 \mathrm{~m}\left(60 \mathrm{~m}^{2}\right)$ strip of Napier grass separated by a $2 \mathrm{~m}$ vegetation-free alley on all sides and eight subplots, with dimensions of $1.75 \mathrm{~m} \times 2.6 \mathrm{~m}$ $\left(\sim 4.55 \mathrm{~m}^{2}\right)$, of which seven were sown with wildflower mixes and one subplot had spontaneous vegetation growth as the control. Buffer plots were a minimum of $150 \mathrm{~m}$ apart. Ten plots were located adjacent to woodland and nine were adjacent to agricultural fields. For the purpose of this study, we analyzed data from subplots sown with the three commercial wildflower mixes, purchased in fall of 2015. The commercial seed mixes were specific to southeastern USA, and included: Southeast wildflower Seed Mix: "eden"-Eden Brothers ${ }^{\circledR}$ (Arden, NC, USA), "ameri"-American Meadows ${ }^{\circledR}$ (Shelburne, VT, USA), and “high"-High Country Gardens ${ }^{\circledR}[36]$ (Table 1).

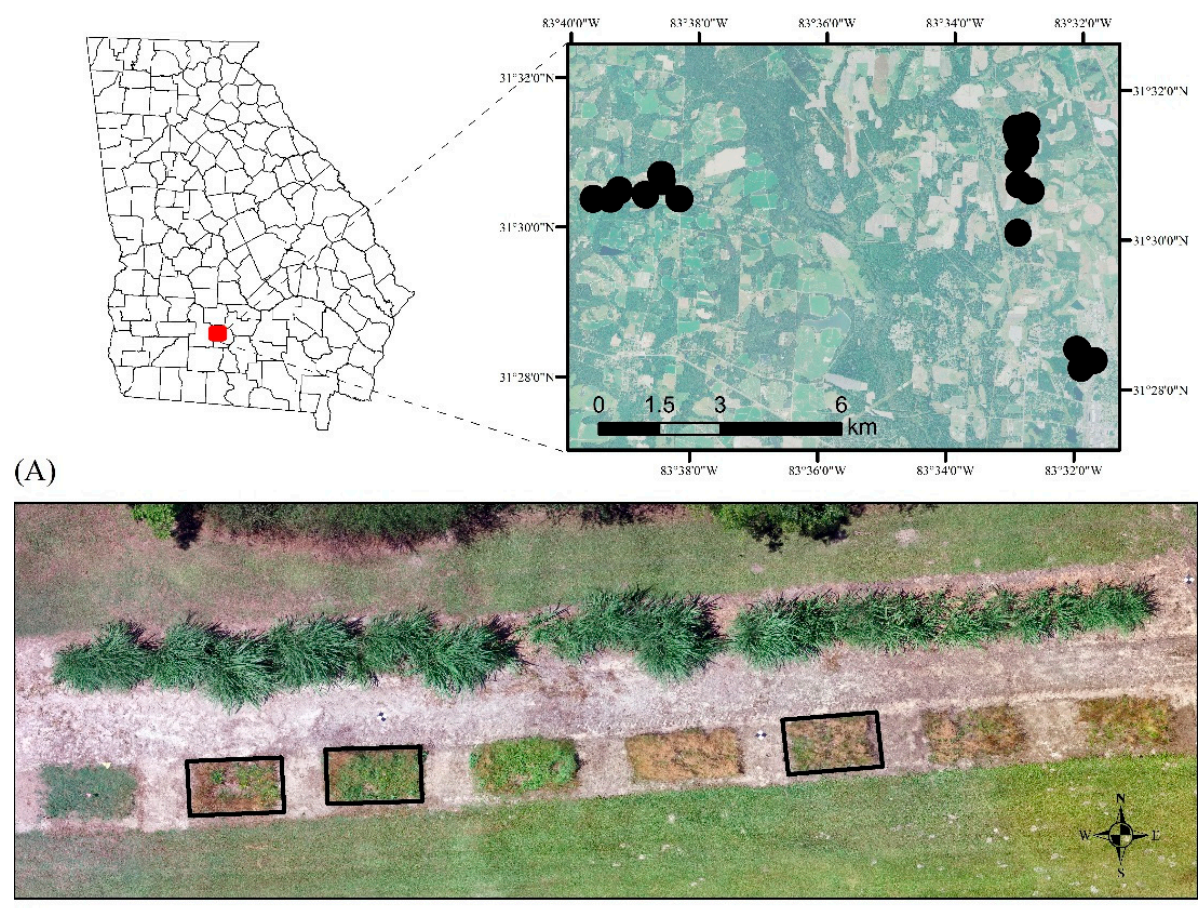

(B)

Figure 1. Location map. The distribution of buffer plots across the experimental farm stations of University of Georgia near Tifton, Georgia (A), and one of the experimental plots showing three subplots (outlined in black) sown with wildflower mixes (B).

\subsection{UAV Mission Preparation}

Prior to data collection, high-resolution orthomosaics were created for each plot to serve as reference maps against which later imagery could be georeferenced. We established six ground control points (GCPs) per plot using a Trimble ${ }^{\circledR}$ Geo7x GPS system $(\mathrm{DOP}<2 \mathrm{~cm}$ ) and placed a highly visible whisker and nail marker at each of these points to serve as temporary geo-located monuments for the duration of the study. Black and white $18 \mathrm{~cm}$ square laminated targets were centered on the GCPs prior to every UAV flight. On 2-3 May 2017, a DJI ${ }^{\circledR}$ Matrice M100 drone with a ZenmuseX3 camera was flown over each plot at a height of $9.14 \mathrm{~m}$, and overlapping imagery of each plot was collected. The imagery was processed using Pix $4 \mathrm{D}^{\circledR}$ Pro with GCPs and produced a very high-resolution $(0.004 \mathrm{~m})$ 
orthomosaic reference image for each plot (average root mean square [RMS] error $\sim 0.009$ ), which was used to georeference the image mosaics of the plots in bloom.

\subsection{Image Acquisition}

Images were captured from the 19 plots to provide data on each of the three commercial mix subplots on two dates, in June and September 2017. Sampling dates represented the peak bloom period in June, observed in a prior study of the same wildflower mixes, and a contrasting date in September, where previously we also observed very low numbers and diversity of flowers blooming [36] (Table 1). While radiometric correction and calibration is usually performed with multi- and hyper-spectral remotely sensed imagery [37], neither the measurement of changes in reflectance, nor absolute radiance were goals of this research. Rather, we were interested in comparing basic imagery from a UAV using limited processing, with field measurements of organisms, although we purposefully planned our image acquisition to minimize the variability in illumination from one flight to the next. To reduce the relative differences in reflectance due to changing illumination, plots were flown in rapid succession, within a 2-day window, during periods of low cloud cover, which was commonly between 0900 and 1400 local time. Lighting conditions were further controlled by sequencing flights to avoid any shading of the plots from nearby trees or structures; the very low altitude of the flights reduced potential effects of light attenuation by haze. The commercially available UAV, Solo-3DR ${ }^{\circledR}$ equipped with a GoPro Hero $4{ }^{\circledR}$ was used to capture images of each plot. The GoPro Hero $4^{\circledR}$ is a small 12-megapixel camera with a red, green and blue (RGB) filter array. No additional filters were used, and the camera was set to a nadir viewing angle throughout the flights. Prior to each flight, the ground control targets were placed over the GCP monuments located in the plot. The UAV was manually controlled using a navigation controller interfaced with a tablet computer and flown at a low altitude of $9.14 \mathrm{~m}$ above the plot to capture images of the subplots. The images were captured with $70 \%$ overlap between images to allow for co-registration.

\subsection{Image Processing and Analysis}

For each plot, imagery from the UAV flights was mosaicked using Photoscan professional (Agisoft ${ }^{\circledR}$ LLC) [38]. Using ArcGIS ArcMap (advanced, v. 10.5; Esri ${ }^{\circledR}$ ) geographic information system (GIS) software, the image mosaics were then related to the reference images at the coordinates of the six GCPs, visible as the black and white targets in the imagery. A first-order polynomial transformation was used to georeferenced the images, and a nearest neighbor technique was used to resample the raster datasets to produce the final georeferenced images. The georeferenced images were then classified into three classes (flowers, non-flowering vegetation, and bare earth) using a supervised maximum likelihood classification algorithm [39]. To do this, polygons outlining pixels of similar values in each class type, i.e., training samples, were used to produce definitions of classes for June and September images respectively. Classifier definitions were then used to segment the UAV imagery and produce classified images of each plot for each date. Classified imagery was subsequently validated by visually comparing 70 points, distributed using a random stratified approach with a minimum of 10 points per class, with the UAV imagery. A confusion matrix was computed using the Segmentation and Classification toolset of ArcGIS [40], producing values for errors of commission and omission, an overall classification accuracy, and a Kappa coefficient [41]. The accuracy of each classification was evaluated based on raw accuracy assessments and the Kappa coefficient, considering values of $>80 \%$ accuracy and $>0.8 \mathrm{Kappa}$ as acceptable. The resolution of the raw UAV image pixels averaged 0.009 $\mathrm{m}$, and varied slightly from plot to plot $( \pm 0.001 \mathrm{~m}$ std. dev.) due to small differences in the flight plans, terrain and wind conditions of individual flights. To create a more uniform data set across all plots for both times, the classified images were resampled to a pixel resolution of $0.01 \times 0.01 \mathrm{~m}$ using a nearest neighbor resampling technique, and clipped to the boundaries of the subplots. From the final classified image, we summarized the floral area occurring within a quadrat area identical to the quadrats, described below, that were used for manual vegetation and arthropod sampling. 
Table 1. Summary of total counts of flower species observed in subplots containing one of three southeast specific wildflower mixes: "eden"-Eden Brothers ${ }^{\circledR}$ (Arden, NC, USA), “ameri"—American Meadows ${ }^{\circledR}$, (Shelburne, VT, USA), and "high"-High Country Gardens ${ }^{\circledR}$. Values represent total counts for each time period, and final total column represents seasonal totals observed. Flower species are ranked by total seasonal floral production.

\begin{tabular}{|c|c|c|c|c|c|c|c|c|c|c|c|c|c|c|c|c|}
\hline \multirow{2}{*}{ Flower Description } & \multicolumn{3}{|c|}{8 May 2017} & \multicolumn{3}{|c|}{8 June 2017} & \multicolumn{3}{|c|}{10 July 2017} & \multicolumn{3}{|c|}{7 August 2017} & \multicolumn{3}{|c|}{18 September 2017} & \multirow[b]{2}{*}{ Total } \\
\hline & Eden & Ameri & High & Eden & Ameri & High & Eden & Ameri & High & Eden & Ameri & High & Eden & Ameri & High & \\
\hline Gaillardia pulchella & 83 & 121 & 106 & 122 & 119 & 151 & 148 & 182 & 152 & 223 & 289 & 249 & 161 & 202 & 160 & 2468 \\
\hline Rudbeckia hirta & 0 & 1 & 0 & 127 & 160 & 103 & 111 & 131 & 59 & 37 & 28 & 15 & 20 & 23 & 20 & 835 \\
\hline Coreopsis lanceolata & 75 & 49 & 145 & 1 & 0 & 21 & 21 & 10 & 37 & 0 & 0 & 1 & 0 & 1 & 0 & 361 \\
\hline Coreopsis tinctoria & 61 & 7 & 0 & 42 & 24 & 30 & 0 & 0 & 0 & 0 & 0 & 0 & 0 & 0 & 0 & 164 \\
\hline Centaurea cyanus & 69 & 0 & 0 & 27 & 0 & 0 & 0 & 0 & 0 & 0 & 0 & 0 & 0 & 0 & 0 & 96 \\
\hline Rudbeckia gloriosa & 0 & 0 & 0 & 0 & 0 & 0 & 19 & 32 & 0 & 0 & 21 & 0 & 1 & 0 & 0 & 73 \\
\hline Phlox drummondi & 12 & 0 & 0 & 9 & 0 & 0 & 0 & 0 & 0 & 13 & 0 & 0 & 0 & 0 & 0 & 34 \\
\hline Linum grandiflorum & 33 & 0 & 0 & 0 & 0 & 0 & 0 & 0 & 0 & 0 & 0 & 0 & 0 & 0 & 0 & 33 \\
\hline Cosmos sulphureus & 0 & 0 & 0 & 0 & 0 & 0 & 0 & 0 & 0 & 11 & 0 & 0 & 4 & 0 & 0 & 15 \\
\hline Linaria maroccana & 0 & 12 & 2 & 0 & 0 & 0 & 0 & 0 & 0 & 0 & 0 & 0 & 0 & 0 & 0 & 14 \\
\hline Monarda citriodora & 0 & 0 & 0 & 3 & 0 & 6 & 0 & 0 & 1 & 0 & 0 & 0 & 0 & 0 & 0 & 10 \\
\hline Cosmos bipinnatus & 3 & 0 & 0 & 0 & 0 & 0 & 0 & 0 & 0 & 0 & 0 & 0 & 0 & 0 & 0 & 3 \\
\hline Oenothera lamarckiana & 0 & 0 & 0 & 0 & 0 & 0 & 0 & 0 & 0 & 0 & 1 & 0 & 0 & 0 & 0 & 1 \\
\hline Total & 336 & 190 & 253 & 331 & 303 & 311 & 299 & 355 & 249 & 284 & 339 & 265 & 186 & 226 & 180 & 4107 \\
\hline
\end{tabular}




\subsection{Vegetation and Arthropod Sampling}

Vegetation sampling and arthropod sampling were carried out within the same week as image acquisition. Within each subplot, five $0.25 \mathrm{~m}^{2}$ quadrats were established for the sampling of vegetation and arthropods. During each collection event, we randomly selected one of the five $0.25 \mathrm{~m}^{2}$ quadrats, and the numbers of flowers occurring were counted for each species of wildflower. For compound flowers, such as those in Asteraceae, we counted the flower head as one flower. Pollinator visits were quantified by visually observing the flowers within the same quadrat for $3 \mathrm{~min}$. All bees and syrphid flies visiting the flowers were pooled as pollinators. Natural enemies were collected by suction sampling from the same quadrat using a reverse flow leaf blower for $30 \mathrm{~s}$. Spiders and several groups of insect predators (Reduviidae, Geocoridae, Carabidae, Coccinellidae, Dermaptera, and hymenopteran parasitoid wasps) were counted and pooled together to estimate natural enemy density and diversity. The Shannon index $(\mathrm{H})$ was used to estimate diversity based on counts of the families of arthropods observed.

\subsection{Statistical Analysis}

Linear mixed-effects models with nested random effects for sampling date within site were conducted using the 'Ime\{nlme\}' function in R [42]. Response variables were natural log-transformed to satisfy the model adequacy assumptions of linear regression, which greatly improved the distribution of residuals. The package r.squaredglmm $\{$ MuMIn $\}$ was used to extract adjusted $\mathrm{r}^{2}$ values from the prediction model [42]. Of the 19 plot images, one September image was excluded due to distortions from poor image registration, and the image data were excluded from further statistical analyses. During model fitting we also observed a few data points that appeared to be extreme values. We ran a sensitivity analysis on regressions to assess the leverage of a few extreme outliers (i.e., floral count value at 50, UAV area at greater than 0.12 , and two natural enemy samples). Excluding these four outliers had no effect on the significance of models or qualitative interpretation, but model adequacy was improved.

\section{Results}

The image classification protocol was more successful in detecting flowers in June than in September. Georeferencing of the image mosaics resulted in average RMS errors of $0.05 \mathrm{~m}$, with one September image excluded, as noted. The overall classification accuracy for each of the 19 plots ranged between $89 \%$ and $97 \%$ in June and between $80 \%$ and $95 \%$ in September after removing a single plot with low values of $77 \%$ and $76 \%$ in June and September, respectively. The Kappa index in June ranged from 0.84 to 0.96 , except for the outlier mentioned above with a low Kappa index of 0.65 . The floral area obtained from deploying this low-cost drone was significantly correlated with the visually counted estimates of flowers within the $0.25 \mathrm{~m}^{2}$ quadrats (Table 2; Figure 2). UAV-derived estimates of the floral area explained $26 \%$ of the variation in floral counts obtained from visually counting all flowers in the quadrats.

Table 2. Results from fitting linear mixed-effects models using the unmanned aerial vehicle (UAV)-estimated floral area within a quadrat to predict visual estimates of floral counts. UAV-estimated floral area and floral counts were used to explain pollinator visits, and natural enemies observed within quadrats. Response variables were natural logarithm-transformed prior to analysis. Natural enemy diversity was estimated using the Shannon index $(H) . R^{2} c$ represents the conditional $R^{2}$, which describes the proportion of variance explained by the fixed and random factors of the regression with $\mathrm{df}=95$ for each model.

\begin{tabular}{cccccc}
\hline Predictor Variable & Response Variable & Estimate $( \pm$ SE) & $t$-Value & $\mathbf{R}^{2} \mathbf{c}$ & $p$-Value \\
\hline UAV floral area & Floral counts & $13.127( \pm 2.53)$ & 5.192 & 0.26 & $<0.001$ \\
Floral counts & Pollinator counts & $0.031( \pm 0.01)$ & 5.875 & 0.64 & $<0.001$ \\
UAV floral area & Pollinator counts & $6.340( \pm 1.81)$ & 3.502 & 0.51 & 0.0007 \\
\hline
\end{tabular}


Table 2. Cont

\begin{tabular}{cccccc}
\hline Predictor Variable & Response Variable & Estimate $( \pm \mathbf{S E})$ & $\boldsymbol{t}$-Value & $\mathbf{R}^{2} \mathbf{c}$ & $\boldsymbol{p}$-Value \\
\hline Floral counts & Natural enemy counts & $0.019( \pm 0.01)$ & 2.038 & 0.21 & 0.0443 \\
UAV floral area & Natural enemy counts & $2.785( \pm 2.71)$ & 1.025 & na & 0.3079 \\
Floral counts & Natural diversity & $-0.000( \pm 0.002)$ & -0.072 & na & 0.9422 \\
UAV floral area & Natural diversity & $0.977( \pm 0.93)$ & 1.055 & na & 0.2939 \\
\hline
\end{tabular}

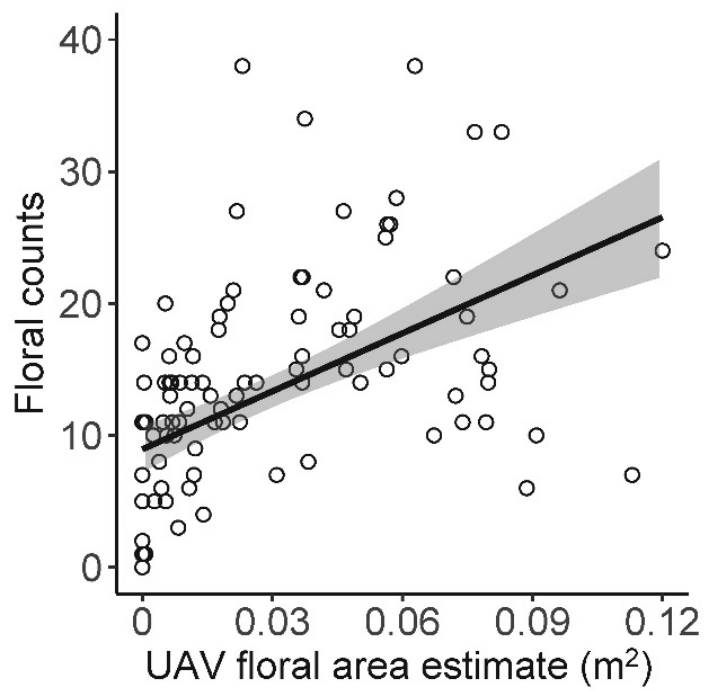

Figure 2. Correlation between floral area extracted from UAV images and visual counts of flowers within a $0.25 \mathrm{~m}^{2}$ quadrat. For ease of interpretation, the line represents the linear relationship between untransformed floral counts with the shaded area indicating $95 \%$ confidence intervals (see Table 2 ).

A total of 196 and 36 pollinators made up of bees, and syrphid flies were observed visiting flowers in June and September, respectively. The floral counts from within the quadrats and UAV-estimated floral area were significantly correlated with number of pollinator visits (Table 2; Figure 3). Similar results were obtained using these estimates of floral resources, and both showed increases in pollinator visits, with greater numbers of flowers or UAV-estimated floral area (Figure 3).
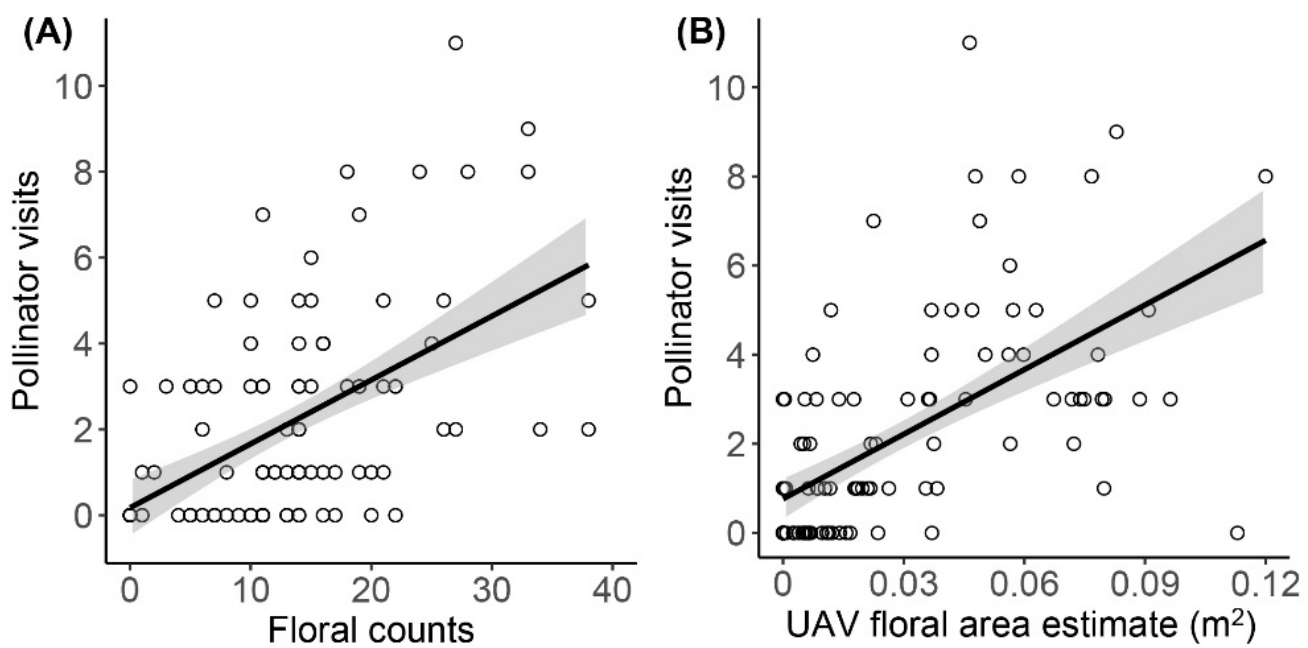

Figure 3. Visual estimates of pollinator activity in $0.25 \mathrm{~m}^{2}$ quadrats in relation to (A) visual counts of flowers within quadrats, and (B) UAV-estimated floral area within the quadrats. For ease of interpretation, lines represent the linear relationship between untransformed floral counts, with shaded areas indicating 95\% confidence intervals (see Table 2). 
A diverse mixture of natural enemies was collected from suction samples in June and September (Table 3). Over the entire season, Araneae, true spiders were the most common, followed by Staphylinidae. The effects of floral counts and UAV-estimated floral area on natural enemy density and diversity were less defined as compared to the pollinators (Figure 4). Natural enemies were very slightly positively correlated with flower counts (Table 2). However, neither natural enemy density nor diversity $(\mathrm{H})$ were correlated with UAV-estimated floral area.

Table 3. Summary of natural enemies observed in wildflower plots collected by suction sampling. Arthropod taxa are organized by seasonal total rank abundance. For each sampling date, values represent: total, mean $( \pm 1 S E)$. Araneae represent all true spiders, and Parasitica represents other parasitoids (i.e., not Braconidae or Ichneumonidae).

\begin{tabular}{cccc}
\hline Date & Total & June & September \\
\hline Araneae & 560 & $201,3.72(0.43)$ & $359,6.65(0.71)$ \\
Staphylinidae & 459 & $20,0.37(0.16)$ & $439,8.13(2.11)$ \\
Parasitica & 82 & $28,0.52(0.16)$ & $54,1.00(0.22)$ \\
Carabidae & 39 & $36,0.67(0.18)$ & $3,0.06(0.04)$ \\
Anthocoridae & 26 & $18,0.33(0.11)$ & $8,0.15(0.07)$ \\
Reduviidae & 23 & $15,0.28(0.09)$ & $8,0.15(0.06)$ \\
Coccinellidae & 17 & $5,0.09(0.05)$ & $12,0.22(0.09)$ \\
Braconidae & 10 & $1,0.02(0.02)$ & $9,0.17(0.05)$ \\
Ichneumonidae & 10 & $4,0.07(0.04)$ & $6,0.11(0.07)$ \\
Nabidae & 8 & $1,0.02(0.02)$ & $7,0.13(0.05)$ \\
Scoliidae & 3 & $3,0.06(0.03)$ & $0,0(0)$ \\
Tiphiidae & 3 & $3,0.06(0.04)$ & $0,0(0)$ \\
Sphecidae & 1 & $0,0.00(0.00)$ & $1,0.02(0.02)$ \\
\hline Totals & 1241 & 335 & 906 \\
\hline
\end{tabular}
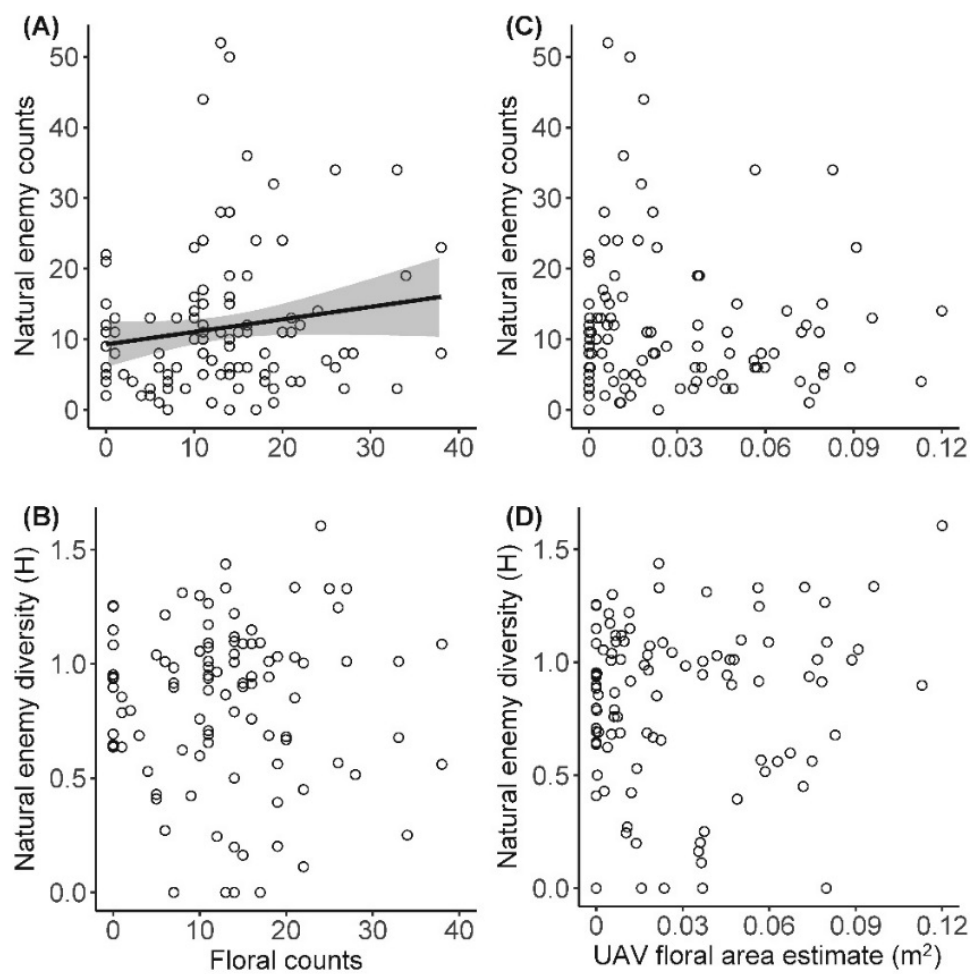

Figure 4. Suction sample estimates of natural enemy density and diversity in relation to visual floral counts within $0.25 \mathrm{~m}^{2}$ quadrats (A,B), and UAV-estimated floral area within the quadrats (C,D). For ease of interpretation, the line represents the linear relationship between untransformed floral counts, with the shaded area indicating 95\% confidence intervals (see Table 2). 


\section{Discussion}

Habitat management to improve beneficial arthropod populations, especially by incorporating native floral resources in agricultural landscapes, has gained momentum in recent years. Consequently, several commercial seed mixes have been designed and are available to support and enhance beneficial arthropod communities. Although floral resources are being implemented, there exist few quantifiable measurements of how much area to plant in a landscape, and what will be the resulting effect of different quantities of floral resources for promoting beneficial arthropod populations [43]. The use of UAVs has increased dramatically in recent years, and they appear to be a feasible approach for assessing floral resources in agricultural landscapes. This study demonstrates the effectiveness of utilizing a low-cost commercial UAVs to quantify floral resources in agricultural landscapes. The UAV data collection, coupled with the image classification system, successfully detected and estimated the floral surface area, and provided a new indirect metric to estimate pollinator populations.

In this study, we achieved moderate to high accuracy in classifying imagery from the UAV by using the supervised maximum likelihood image classification approach. The overall accuracy of the classification was more efficient in June, but still measurable in September, leading to a stronger overall correlation between the floral counts and the floral area, as obtained through the UAV imagery. Müllerová et al. [31] reported that the accuracy of image classification of vegetation depends on spatially registered imagery, coinciding with the period at which the phenological phase of the vegetation is most recognizable, which in this study are the flowers. All the plots in this study had peak bloom periods in June, as opposed to September, and hence the best images were obtained in June, supported also by the acceptable accuracy values and Kappa coefficients. The slightly lower overall accuracy of flower detection in September was likely a result of a major weather event (i.e., Hurricane Irma on 10-11 September 2017 when storm debris in the plots contributed to the misclassification of certain pixels. This study did not examine the spectral characteristics of flower blooms and how well the UAV-borne camera was able to detect blooms under varying conditions of illumination. Furthermore, most blooms in the study happened to be red and yellow, which were easily detected with the RGB camera, so it is unknown how well such a system would function with the detection of blooms emitting in higher frequency ranges of the visible spectrum, e.g., blue and violet, especially in the absence of radiometric and atmospheric corrections. This is a potential area for further research, and it could be of importance to arthropod monitoring, given the importance of ultraviolet floral pattern cues in pollinator behavior [44].

Research increasingly shows that native wildflower plantings support higher native pollinator populations $[6,45,46]$. We used two methods to quantify floral resource availability for pollinators, manual floral counts and estimated floral area using a remote sensing UAV approach. Both approaches provided significant positive correlations with pollinator populations. However, this was not perfect, and UAV-estimated floral area displayed variability in the prediction of floral counts and in the prediction of pollinators. One of the explanations for the variability is that pollinator groups respond to characteristics other than the area of flowers or the numbers of flowers [8,9], and floral characteristics such as corolla length and the amount of pollen and available nectar will not be captured with this UAV approach. Over larger areas, the UAV estimates of floral area should capture a generalized view of the floral resources available to pollinators, and estimates of pollinator visitation, because counting all flowers and floral trait distributions in the landscape is not feasible. Therefore, extracting random samples of an area to estimate floral resources available would be the preferred method for large scale implementation. For manual counts, observer bias $[43,47]$ is an issue, especially with the large teams that would be needed to document floral resource availability at large spatial extents. Results suggested that the number of pollinators in a given area can be indirectly predicted by the amount of floral area estimated in a landscape, and sampled using a UAV with a simple RGB camera. For the current dataset, small increases of even $0.12 \mathrm{~m}^{2}$ of floral area to a landscape should correspond to an increase in 6-8 pollinator visits in that area (Figure 4 ). 
In contrast to the pollinators, observed natural enemy populations were variable and abundances were very slightly correlated with floral counts (Figure 4A). We also found no significant correlations of floral area or counts with natural enemy diversity. In our study, we attempted to predict the response of natural enemy abundance with one floral resource character, the surface area of the flowers; however, natural enemies respond to multiple factors in addition to the presence of floral resources [48]. The importance of a complex natural habitat for natural enemies can vary widely depending on the type of crop, the predator identity, or the functional role, land management, and habitat structure [49]. As a first step in using the UAV approach, we pooled all of the natural enemies as one group and analyzed counts from vacuum samples. This approach may limit our ability to detect responses to diverse habitats [50], where responses may depend on predator functional groups. For instance, spiders may be very attracted to flowers, and carabid beetles may not respond to these resources [51]. Community and functional group analyses were beyond the scope of this initial study. We were primarily interested in developing and testing a UAV approach to indirectly predict arthropod populations, and we used estimates of diversity to represent the community response. Future research will assess the use of UAV technology for characterizing community responses to landscapes and floral resources.

\section{Conclusions}

The approach that we developed and tested using a UAV to quantify floral resources has potential as an efficient method for predicting pollinator populations over large spatial scales. In our study, we found that small increases of floral area $\left(0.12 \mathrm{~m}^{2}\right)$, detected using a low-cost UAV with an RGB camera, corresponded with increases in pollinator visits (6- 8 pollinators). Therefore, this metric has potential as an indicator for decision-making in designing pollinator landscapes for crops or home gardeners. Although our study demonstrated that UAV data are well-suited for detection of floral resources, the processing of the data can still be technically difficult. For instance, images from one plot in September were not usable because of the geometric distortions caused while orthomosaicking the images. The workflow that we implemented could be further refined by automating certain steps, such as classifying referenced imagery in batch processes. Nevertheless, our study provides insights for the practical application of UAVs as efficient tools for quantifying floral resources. Future research should be aimed at integrating the floral resource estimates with decision-making tools for improving habitat structure in landscapes. By this means, rapid assessments of floral resources can be integrated with cropping system plans that promote beneficial arthropod populations and their associated services.

Author Contributions: Conceptualization, S.S.X., D.M.O., J.M.S. and A.W.C.; methodology, S.S.X., D.M.O., J.M.S. and A.W.C; software, J.M.S., A.W.C., and S.S.X.; validation, J.M.S., A.W.C., and S.S.X.; formal analysis, J.M.S., A.W.C., and S.S.X.; investigation, J.M.S., A.W.C., and S.S.X.; resources, J.M.S. and A.W.C.; data curation, J.M.S. and A.W.C.; writing-original draft preparation, S.S.X., D.M.O., J.M.S. and A.W.C.; writing-review and editing, D.M.O., J.M.S. and A.W.C.; visualization, J.M.S. and A.W.C.; supervision, J.M.S., A.W.C. and D.M.O.; project administration, J.M.S.; funding acquisition, J.M.S. and A.W.C.

Funding: This project was supported by the Long Term Agroecosystem Research (LTAR) Network. This project was funded by a cooperative agreement (\# 58-6048-5-013), from the Gulf Atlantic LTAR site of the U.S. Department of Agriculture-Agricultural Research Service and administered by the University of Georgia.

Acknowledgments: We thank Coby Smith, who provided guidance on UAV mission planning and execution, established ground control coordinates, flew baseline UAV missions, and provided high resolution ortho-imagery for image georeferencing and classification. We also thank Andy Hornbuckle, Melissa Thompson, Andres Contreras, Austen DeLoach, Pam Halliday, Avery Mathis, Kameron Swain, Carter Turner, and Andy Carter for their help in plot establishment/maintenance, sampling, sorting, and recording arthropods. We are also grateful to Aaron Bruce, Jobe Threewit, and Coby Smith for helping with initial plot surveying and mapping.

Conflicts of Interest: The authors declare no conflict of interest. Mention of company or trade names is for description only and does not imply endorsement by the U.S. Department of Agriculture. The U.S. Department of Agriculture is an equal opportunity provider and employer. 


\section{References}

1. Gurr, G.M.; Wratten, S.D.; Landis, D.A.; You, M. Habitat management to suppress pest populations: Progress and prospects. Annu. Rev. Entomol. 2017, 62, 91-109. [CrossRef] [PubMed]

2. Landis, D.A. Designing agricultural landscapes for biodiversity-based ecosystem services. Basic Appl. Ecol. 2017, 18, 1-12. [CrossRef]

3. Tschumi, M.; Albrecht, M.; Bärtschi, C.; Collatz, J.; Entling, M.H.; Jacot, K. Perennial, species-rich wildflower strips enhance pest control and crop yield. Agric. Ecosyst. Environ. 2016, 220, 97-103. [CrossRef]

4. Tschumi, M.; Albrecht, M.; Collatz, J.; Dubsky, V.; Entling, M.H.; Najar-Rodriguez, A.J.; Jacot, K. Tailored flower strips promote natural enemy biodiversity and pest control in potato crops. J. Appl. Ecol. 2016, 53, 1169-1176. [CrossRef]

5. Hatt, S.; Lopes, T.; Boeraeve, F.; Chen, J.; Francis, F. Pest regulation and support of natural enemies in agriculture: Experimental evidence of within field wildflower strips. Ecol. Eng. 2017, 98, 240-245. [CrossRef]

6. Balzan, M.V.; Bocci, G.; Moonen, A.C. Utilisation of plant functional diversity in wildflower strips for the delivery of multiple agroecosystem services. Entomol. Exp. Appl. 2016, 158, 304-319. [CrossRef]

7. Martin, E.A.; Seo, B.; Park, C.R.; Reineking, B.; Steffan-Dewenter, I. Scale-dependent effects of landscape composition and configuration on natural enemy diversity, crop herbivory, and yields. Ecol. Appl. 2016, 26, 448-462. [CrossRef] [PubMed]

8. Fiedler, A.K.; Landis, D.A. Plant characteristics associated with natural enemy abundance at Michigan native plants. Environ. Entomol. 2007, 36, 878-886. [CrossRef] [PubMed]

9. Tuell, J.K.; Fiedler, A.K.; Landis, D.; Isaacs, R. Visitation by wild and managed bees (Hymenoptera: Apoidea) to Eastern U.S. Native plants for use in conservation programs. Environ. Entomol. 2008, 37, 707-718. [CrossRef]

10. Thorp, K.; Dierig, D. Color image segmentation approach to monitor flowering in lesquerella. Ind. Crop. Prod. 2011, 34, 1150-1159. [CrossRef]

11. Fritz, S.; See, L.; McCallum, I.; You, L.; Bun, A.; Moltchanova, E.; Duerauer, M.; Albrecht, F.; Schill, C.; Perger, C. Mapping global cropland and field size. Glob. Chang. Biol. 2015, 21, 1980-1992. [CrossRef] [PubMed]

12. Eberhardt, I.D.R.; Schultz, B.; Rizzi, R.; Sanches, I.D.A.; Formaggio, A.R.; Atzberger, C.; Mello, M.P.; Immitzer, M.; Trabaquini, K.; Foschiera, W.; et al. Cloud cover assessment for operational crop monitoring systems in tropical areas. Remote Sens. 2016, 8, 219. [CrossRef]

13. Anderson, K.; Gaston, K.J. Lightweight unmanned aerial vehicles will revolutionize spatial ecology. Front. Ecol. Environ. 2013, 11, 138-146. [CrossRef]

14. Cruzan, M.B.; Weinstein, B.G.; Grasty, M.R.; Kohrn, B.F.; Hendrickson, E.C.; Arredondo, T.M.; Thompson, P.G. Small unmanned aerial vehicles (micro-uavs, drones) in plant ecology. Appl. Plant Sci. 2016, 4, 1600041. [CrossRef] [PubMed]

15. Zhang, C.; Kovacs, J.M. The application of small unmanned aerial systems for precision agriculture: A review. Precis. Agric. 2012, 13, 693-712. [CrossRef]

16. Hardin, P.J.; Hardin, T.J. Small-scale remotely piloted vehicles in environmental research. Geogr. Compass 2010, 4, 1297-1311. [CrossRef]

17. Lelong, C.C.; Burger, P.; Jubelin, G.; Roux, B.; Labbé, S.; Baret, F. Assessment of unmanned aerial vehicles imagery for quantitative monitoring of wheat crop in small plots. Sensors 2008, 8, 3557-3585. [CrossRef] [PubMed]

18. Rango, A.; Laliberte, A.; Herrick, J.E.; Winters, C.; Havstad, K.; Steele, C.; Browning, D. Unmanned aerial vehicle-based remote sensing for rangeland assessment, monitoring, and management. J. Appl. Remote Sens. 2009, 3, 033542. [CrossRef]

19. Biradar, B.V.; Shrikhande, S.P. Flower detection and counting using morphological and segmentation technique. Int. J. Comput. Sci. Inf. Technol. 2015, 6, 2498-2501.

20. Siraj, F.; Salahuddin, M.A.; Yusof, S.A.M. Digital image classification for malaysian blooming flower. In Proceedings of the 2010 Second International Conference on Computational Intelligence, Modelling and Simulation (CIMSiM), Tuban, Indonesia, 28-30 September 2010; pp. 33-38. 
21. Thorp, K.; Wang, G.; Badaruddin, M.; Bronson, K. Lesquerella seed yield estimation using color image segmentation to track flowering dynamics in response to variable water and nitrogen management. Ind. Crop. Prod. 2016, 86, 186-195. [CrossRef]

22. Swain, K.C.; Thomson, S.J.; Jayasuriya, H.P. Adoption of an unmanned helicopter for low-altitude remote sensing to estimate yield and total biomass of a rice crop. Trans. ASABE 2010, 53, 21-27. [CrossRef]

23. Hunt, E.R.; Cavigelli, M.; Daughtry, C.S.; Mcmurtrey, J.E.; Walthall, C.L. Evaluation of digital photography from model aircraft for remote sensing of crop biomass and nitrogen status. Precis. Agric. 2005, 6, 359-378. [CrossRef]

24. Agüera, F.; Carvajal, F.; Pérez, M. Measuring sunflower nitrogen status from an unmanned aerial vehicle-based system and an on the ground device. Int. Arch. Photogramm. Remote Sens. Spat. Inf. Sci. 2011, 38, 33-37. [CrossRef]

25. Lehmann, J.R.K.; Nieberding, F.; Prinz, T.; Knoth, C. Analysis of unmanned aerial system-based images in forestry-A new perspective to monitor pest infestation levels. Forests 2015, 6, 594-612. [CrossRef]

26. Näsi, R.; Honkavaara, E.; Lyytikäinen-Saarenmaa, P.; Blomqvist, M.; Litkey, P.; Hakala, T.; Viljanen, N.; Kantola, T.; Tanhuanpää, T.; Holopainen, M. Using uav-based photogrammetry and hyperspectral imaging for mapping bark beetle damage at tree-level. Remote Sens. 2015, 7, 15467-15493. [CrossRef]

27. Cunliffe, A.M.; Brazier, R.E.; Anderson, K. Ultra-fine grain landscape-scale quantification of dryland vegetation structure with drone-acquired structure-from-motion photogrammetry. Remote Sens. Environ. 2016, 183, 129-143. [CrossRef]

28. Calvario, G.; Sierra, B.; Alarcón, T.E.; Hernandez, C.; Dalmau, O. A multi-disciplinary approach to remote sensing through low-cost uavs. Sensors 2017, 17, 1411. [CrossRef] [PubMed]

29. Fang, S.; Tang, W.; Peng, Y.; Gong, Y.; Dai, C.; Chai, R.; Liu, K. Remote estimation of vegetation fraction and flower fraction in oilseed rape with unmanned aerial vehicle data. Remote Sens. 2016, 8, 416. [CrossRef]

30. Severtson, D.; Callow, N.; Flower, K.; Neuhaus, A.; Olejnik, M.; Nansen, C. Unmanned aerial vehicle canopy reflectance data detects potassium deficiency and green peach aphid susceptibility in canola. Precis. Agric. 2016, 17, 659-677. [CrossRef]

31. Müllerová, J.; Bartaloš, T.; Brůna, J.; Dvořák, P.; Vítková, M. Unmanned aircraft in nature conservation: An example from plant invasions. Int. J. Remote Sens. 2017, 38, 2177-2198. [CrossRef]

32. Michez, A.; Piégay, H.; Jonathan, L.; Claessens, H.; Lejeune, P. Mapping of riparian invasive species with supervised classification of unmanned aerial system (UAS) imagery. Int. J. Appl. Earth Obs. Geoinf. 2016, 44, 88-94. [CrossRef]

33. Hill, D.J.; Tarasoff, C.; Whitworth, G.E.; Baron, J.; Bradshaw, J.L.; Church, J.S. Utility of unmanned aerial vehicles for mapping invasive plant species: A case study on yellow flag Iris (Iris pseudacorus L.). Int. J. Remote Sens. 2017, 38, 2083-2105. [CrossRef]

34. Carl, C.; Landgraf, D.; van der Maaten-Theunissen, M.; Biber, P.; Pretzsch, H. Robinia pseudoacacia L. flowers analyzed by using Unmanned Aerial Vehicle (UAV). Remote Sens. 2017, 9, 1091. [CrossRef]

35. Lino, A.C.L.; Sanches, J.; Moraes, G.; Dias-Tagliacozzo, I.; Augusto, F.; LIMA, B.; Nascimento, T.S. Flower classification supported by digital imaging techniques. J. Inf. Technol. Agric. 2011, 4, 1-6.

36. Xavier, S.S.; Olson, D.M.; Coffin, A.W.; Strickland, T.C.; Schmidt, J.M. Perennial grass and native wildflowers: A synergistic approach to habitat management. Insects 2017, 8, 104. [CrossRef] [PubMed]

37. Lillesand, T.M.; Kiefer, R.W.; Chipman, J.W. Remote Sensing and Image Interpretation; Wiley: New York, NY, USA, 2004; Volume 5.

38. Agisoft. Agisoft Photoscan User Manual: Professional Edition, version 1.1; Agisoft, L.L.C.: St. Petersburg, Russia, 2014.

39. Foody, G.M.; Campbell, N.; Trodd, N.; Wood, T. Derivation and applications of probabilistic measures of class membership from the maximum-likelihood classification. Photogramm. Eng. Remote Sens. 1992, 58, 1335-1341.

40. Environmental System Research Institute (ESRI). Arcgis Desktop: Release 10.5.1; Environmental System Research Institute: Redlands, CA, USA, 2017.

41. Fitzgerald, R.; Lees, B. Assessing the classification accuracy of multisource remote sensing data. Remote Sens. Environ. 1994, 47, 362-368. [CrossRef]

42. RCoreTeam. R: A Language and Environment for Statistical Computing; R Foundation for Statistical Computing: Vienna, Austria, 2017. 
43. Szigeti, V.; Kőrösi, Á.; Harnos, A.; Nagy, J.; Kis, J. Measuring floral resource availability for insect pollinators in temperate grasslands-A review. Ecol. Entomol. 2016, 41, 231-240. [CrossRef]

44. Wakakuwa, M.; Stavenga, D.G.; Arikawa, K. Spectral organization of ommatidia in flower-visiting insectst. Photochem. Photobiol. 2007, 83, 27-34. [CrossRef] [PubMed]

45. Venturini, E.M.; Drummond, F.A.; Hoshide, A.K.; Dibble, A.C.; Stack, L.B. Pollination reservoirs for wild bee habitat enhancement in cropping systems: A review. Agroecol. Sustain. Food Syst. 2017, 41, 101-142. [CrossRef]

46. Williams, N.M.; Ward, K.L.; Pope, N.; Isaacs, R.; Wilson, J.; May, E.A.; Ellis, J.; Daniels, J.; Pence, A.; Ullmann, K. Native wildflower plantings support wild bee abundance and diversity in agricultural landscapes across the united states. Ecol. Appl. 2015, 25, 2119-2131. [CrossRef] [PubMed]

47. Szigeti, V.; Kőrösi, Á.; Harnos, A.; Nagy, J.; Kis, J. In Comparing two methods for estimating floral resource availability for insect pollinators in semi-natural habitats. Ann. Soc. Entomol. Fr. (NS) 2016, 52, $289-299$. [CrossRef]

48. Hatt, S.; Boeraeve, F.; Artru, S.; Dufrêne, M.; Francis, F. Spatial diversification of agroecosystems to enhance biological control and other regulating services: An agroecological perspective. Sci. Total. Environ. 2018, 621, 600-611. [CrossRef] [PubMed]

49. Tscharntke, T.; Karp, D.S.; Chaplin-Kramer, R.; Batáry, P.; DeClerck, F.; Gratton, C.; Hunt, L.; Ives, A.; Jonsson, M.; Larsen, A. When natural habitat fails to enhance biological pest control-five hypotheses. Biol. Conserv. 2016, 204, 449-458. [CrossRef]

50. McCabe, E.; Loeb, G.; Grab, H. Responses of crop pests and natural enemies to wildflower borders depends on functional group. Insects 2017, 8, 73. [CrossRef] [PubMed]

51. Shackelford, G.; Steward, P.R.; Benton, T.G.; Kunin, W.E.; Potts, S.G.; Biesmeijer, J.C.; Sait, S.M. Comparison of pollinators and natural enemies: A meta-analysis of landscape and local effects on abundance and richness in crops. Biol. Rev. 2013, 88, 1002-1021. [CrossRef] [PubMed]

(C) 2018 by the authors. Licensee MDPI, Basel, Switzerland. This article is an open access article distributed under the terms and conditions of the Creative Commons Attribution (CC BY) license (http:/ / creativecommons.org/licenses/by/4.0/). 